\title{
Metallothionein Isoform Expression in Benign and Malignant Thyroid Lesions
}

\author{
BEATA WOJTCZAK ${ }^{1 *}$, BARTOSZ PULA ${ }^{2 *}$, AGNIESZKA GOMULKIEWICZ ${ }^{2}$, \\ MATEUSZ OLBROMSKI ${ }^{2}$, MARZENA PODHORSKA-OKOLOW ${ }^{2}$, PAWEŁ DOMOSLAWSKI ${ }^{1}$, \\ MAREK BOLANOWSKI ${ }^{3}$, JACEK DAROSZEWSKI ${ }^{3}$ and PIOTR DZIEGIEL ${ }^{2,4}$ \\ ${ }^{1}$ First Department and Clinic of General, Gastroenterological and Endocrine Surgery, \\ ${ }^{2}$ Department of Histology and Embryology, ${ }^{3}$ Department and Clinic of Endocrinology, \\ Diabetology and Isotope Therapy, Wroclaw Medical University, Wroclaw, Poland; \\ ${ }^{4}$ Department of Physiotherapy, Wroclaw University School of Physical Education, Wroclaw, Poland
}

\begin{abstract}
Background: Metallothioneins (MTs) are involved in numerous cell processes such as binding and transport of zinc and copper ions, differentiation, proliferation and apoptosis, therefore contributing to carcinogenesis. Scarce data exist on their expression in benign and malignant lesions of the thyroid. Materials and Methods: $m R N A$ expression of functional isoforms of MT genes (MT1A, MT1B, MT1E, MT1F, MT1G, MT1H, MT1X, MT2A, MT4) was studied in 17 nodular goiters (NG), 12 follicular adenomas (FA) and 26 papillary thyroid carcinomas (PTC). Results: One-way ANOVA revealed significant differences in mRNA expression levels of MT1A $(p<0.05), \quad M T 1 E$ $(p<0.005), M T 1 F(p<0.0001), M T 1 G(p<0.005), M T 1 X$ $(p<0.0005)$ and MT2A $(p<0.005)$ in the analyzed samples. Post hoc analysis confirmed a significantly lower expression of MTIA mRNA in PTC compared to $N G(p<0.05)$. Significant down-regulation was also noted for other MT isoforms in PTC in comparison to NG: MTIE $(p<0.05)$, $\operatorname{MTlF}(p<0.0001), M T 1 G(p<0.005), \operatorname{MTlX}(p<0.0005)$ and $M T 2 A(p<0.05)$. In addition, significant down-regulation of $M T I F$ and MTIG in FA compared to $N G$ was observed $(p<0.005$ and $p<0.05$, respectively). Conclusion: Expression of functional MT isoforms may contribute to thyroid carcinogenesis and potentially serve as a diagnostic marker in distinguishing benign and malignant lesions.
\end{abstract}

*These Authors contributed equally to this study.

Correspondence to: Beata Wojtczak, MD, Ph.D., 1st Department and Clinic of General, Gastroenterological and Endocrine Surgery, Wroclaw Medical University, M.C. Sklodowskiej 66 Str., 50-369 Wroclaw, Poland. Tel: +48 717842162, Fax: +48 713270929, email: beatawojtczak@wp.pl

Key Words: Metallothioneins, thyroid gland, papillary thyroid carcinoma.
Nodular goiter (NG) is one of the most common iodine intake-dependent endocrine disorders, as thyroid nodules can be palpated in approximately $4-7 \%$ of adults (1). With advancements of ultrasound technique and more widespread access to imaging, incidental diagnoses of thyroid nodules have increased to include up to $20 \%$ of the general population (2). The incidence rate of thyroid neoplasms in Poland has grown substantially in the past two decades and was 2,192 cases in 2010. This incidence rate increases with age up to the seventh decade of life, and decreases thereafter (3).

It is of great importance to distinguish benign from malignant lesions before surgical treatment because thyroid operations are associated with dangerous complications such as recurrent laryngeal nerve palsy and hypoparathyroidism. Fine-needle aspiration (FNA) biopsy of the thyroid is routinely used in preoperative diagnostic examination for thyroid nodules (4). However, FNA biopsy has certain limitations, as up to $40 \%$ of cases are diagnosed as of indeterminate malignancy (follicular neoplasms) $(5,6)$. Firstly, there is no possibility of differentiating a follicular adenoma (FA) from a follicular thyroid carcinoma (FTC) upon cytological assessment. In order to diagnose FTC, it is necessary to assess capsule infiltration and vascular invasion during histopathological examination (7). All patients with indeterminate cytology undergo surgical treatment, with only $10-20 \%$ ultimately having a diagnosis of malignant disease, meaning $80-90 \%$ could have avoided surgical treatment if an appropriate marker were available. Secondly, it is very difficult to effectively control all nodular lesions in multinodular goiter, as very often papillary thyroid carcinoma (PTC) are diagnosed in histopathological examination (8). The overall incidence of thyroid carcinomas in those with potentially benign thyroid lesions is up to $17.2 \%$ of resected cases, however, incidental thyroid carcinomas are prevalent in up to $35.6 \%$ upon autopsy examination $(9,10)$. 
Therefore, identification of potential markers of malignancy in thyroid nodules in the form of single or multiple molecular targets is of upmost importance. Metallothioneins (MTs) may be potentially useful markers in this clinical setting. Metallothioneins are intracellular low molecular weight proteins (6-7 kDa) first isolated in 1957 from horse renal cortex, and are expressed both in normal as well in neoplastic cells $(11,12)$. All MT isoforms posses a highly conserved amino acid sequence and show minimal structural differences. A single MT molecule consists of 6168 amino acids, depending on the isoform, where up to onethird of the protein sequence is composed of cysteine residues (13-15). Two domains are distinguished, the $\mathrm{C}$ terminal $\alpha$ and the $\mathrm{N}$-terminal $\beta$, which are linked each other by a lysine dimer. MTs are divided into four principal isoforms, MT1, MT2, MT3 and MT4 (16). At least 11 MT genes code for functional proteins namely $M T 1 A, M T 1 B$, MT1E, MT1F, MT1G, MT1H, MT1M, MT1X, MT2A, MT3 and MT4 (16-18). MT1C, MT1D, MT1I, MT1J, MT1K, MT1L and $M T 2 B$ are non-coding pseudogenes with unknown functionality $(14,16,19)$.

Due to their high cysteine content, MTs are involved in numerous cell processes such as binding and transport of zinc and copper ions, detoxification of heavy metals, scavenging of free radicals, and cell differentiation, proliferation and apoptosis $(14,20,21)$. Furthermore, MT1, MT2 and MT3 may protect cells from certain chemotherapeutic agents or radiation-induced damage (22, 23). Several studies reported increased expression of MTs in cancer such as of breast, kidney, lung, nosopharynx, ovary, prostate and salivary glands $(13,20)$.

The first study regarding MT expression in normal thyroid tissues was performed by Nartney et al. in the late 1980s. They revealed that in paraffin-embedded tissues of normal thyroid, only $20 \%$ of analyzed cases expressed MT in the nucleus of follicular thyroid cells, whereas a nuclearcytoplasmic expression pattern was noted in majority of surgically resected tumor samples (91\%) (24). Nevertheless, other reports indicate that MT expression is highly variable dependent on the particular lesion type, but in most cases it is down-regulated in thyroid cancer as compared to normal and benign thyroid lesions (25-28). In the study of Królicka et al., the highest expression of MT1 and 2 was detected in FTC and the lowest in medullary carcinoma. Its expression was also significantly elevated in FTC as compared to FA and may be potentially utilized as a biomarker of distinguishing both these lesions (25). Moreover, Ferrario et al. identified the MT1G isoform as a potent oncosuppressor of thyroid carcinogenesis (26).

Taking into account the biological role of MT and up until now performed studies we investigated the mRNA expression functional MT isoforms genes (MT1A, MT1B, MT1E, MT1F, MT1G, MT1H, MT1X, MT2A, MT4) in benign
Table I. Clinical and pathological characteristics of the analyzed patients.

\begin{tabular}{lccc}
\hline Characteristic & $\begin{array}{c}\text { Nodular } \\
\text { goiter }\end{array}$ & $\begin{array}{c}\text { Follicular } \\
\text { adenoma }\end{array}$ & $\begin{array}{c}\text { Papillary thyroid } \\
\text { carcinoma* }\end{array}$ \\
\hline Age (range), years & $\begin{array}{c}49.59 \pm 14.31 \\
(27-81)\end{array}$ & $\begin{array}{c}49.25 \pm 17.65 \\
(23-87)\end{array}$ & $\begin{array}{c}54.23 \pm 14.31 \\
(27-81)\end{array}$ \\
Gender, n & 1 & 2 & 5 \\
Male & 16 & 10 & 21 \\
Female & & & \\
pT, n & & & 10 \\
pT1 & & & 5 \\
pT2 & & & 1 \\
pT3 & & & 6 \\
pT4 & & & 15 \\
pN, n & & 7 \\
pN- & & & \\
pN+ & & & \\
\hline
\end{tabular}

*pT and $\mathrm{pN}$ characteristics missing in four cases.

and malignant thyroid tissues in order to assess their potency in discriminating between these lesion types.

\section{Materials and Methods}

Patients and clinical samples. The studies were performed on thyroid tissue samples collected during thyroidectomy procedures at the First Department of General, Gastroenterological and Endocrinological Surgery of Wroclaw Medical University, Poland, in the years 2009-2011. The study group comprised 17 NG, 12 FA and 26 PTC. The clinical and pathological data of the patients are summarized in Table I.

The resected tissue fragments were divided into two parts. One was fixed in $10 \%$ buffered formalin, dehydrated, embedded in paraffin and subsequently hematoxylin and eosin (HE) staining was performed to verify the diagnosis, and qualify the sample for the molecular studies. The second was collected in RNAlater (Invitrogen, Carlsbad, CA, USA) and stored at $-80^{\circ} \mathrm{C}$ until RNA isolation was performed.

RNA extraction, cDNA synthesis and real-time polymerase chain reaction $(P C R)$. Total RNA was extracted from thyroid samples stored in RNAlater using the RNeasy Mini Kit (Qiagen, Hilden, Germany) according to the procedures recommended by the manufacturer. DNase (Qiagen) digestion was performed to remove genomic DNA. The quality of the RNA samples was evaluated utilizing agarose gels and ethidium bromide staining for visualization of $18 \mathrm{~S}$ and $28 \mathrm{~S}$ bands under UV light. Concentration and quality of the isolated RNA was measured in a NanoDrop1000 instrument (NanoDrop Technologies, Wilmington, MA, USA). Reverse transcription was performed using SuperScript III (Invitrogen) according to the manufacturer's protocol.

Subsequently, mRNA expression levels of the functional MT isoforms were evaluated with use of real-time PCR, performed in a 7900HT Fast Real-Time PCR System using the TaqMan ${ }^{\circledR}$ Gene 
Table II. Relative mRNA expression of the analyzed metallothionein (MT) isoforms. Differences in expression were analyzed using one-way ANOVA. Data are presented as the mean \pm standard deviation (median).

\begin{tabular}{|c|c|c|c|c|}
\hline MT isoform & Nodular goiter & Follicular adenoma & Papillary thyroid carcinoma & $p$-Value \\
\hline MT1A & $1.42 \pm 1.30(1.13)$ & $1.09 \pm 1.12(0.44)$ & $0.53 \pm 0.43(0.39)$ & $<0.05$ \\
\hline$M T 1 B$ & $43.45 \pm 149.1(0.34)$ & $16.89 \pm 39.15(0.09)$ & $4.11 \pm 11.81(0.13)$ & ns \\
\hline MT1E & $1.59 \pm 1.47(1.21)$ & $0.32 \pm 0.36(0.23)$ & $0.66 \pm 1.18(0.22)$ & $<0.005$ \\
\hline$M T 1 F$ & $1.49 \pm 1.29(0.85)$ & $0.32 \pm 0.42(0.11)$ & $0.29 \pm 0.55(0.07)$ & $<0.0001$ \\
\hline$M T 1 G$ & $2.33 \pm 3.02(1.60)$ & $0.43 \pm 0.51(0.30)$ & $0.40 \pm 1.24(0.04)$ & $<0.005$ \\
\hline$M T 1 H$ & $8.97 \pm 20.58(2.53)$ & $2.95 \pm 8.49(0.19)$ & $0.92 \pm 4.19(0.01)$ & ns \\
\hline $\operatorname{MT1X}$ & $1.14 \pm 0.75(1.01)$ & $0.60 \pm 0.48(0.58)$ & $0.35 \pm 0.41(0.18)$ & $<0.0005$ \\
\hline$M T 2 A$ & $1.49 \pm 0.88(1.27)$ & $0.73 \pm 0.64(0.61)$ & $0.81 \pm 0.72(0.61)$ & $<0.05$ \\
\hline MT3 & $8.35 \pm 20.04(0.93)$ & $68.08 \pm 187.9(3.86)$ & $0.48 \pm 0.26(0.45)$ & ns \\
\hline
\end{tabular}

ns: Not significant.

Table III. Correlations between mRNA expression of analyzed functional metallothionein (MT) isoforms in nodular goiter cases.

\begin{tabular}{|c|c|c|c|c|c|c|c|c|}
\hline Isoform & $M T 1 B$ & $M T 1 E$ & $M T 1 F$ & $M T 1 G$ & $M T 1 H$ & $M T 1 X$ & $M T 2 A$ & MT3 \\
\hline \multirow[t]{2}{*}{ MT1A } & $\mathrm{r}=0.46$ & $\mathrm{r}=0.43$ & $\mathrm{r}=0.53$ & $\mathrm{r}=0.36$ & $\mathrm{r}=0.40$ & $\mathrm{r}=0.44$ & $\mathrm{r}=0.42$ & $\mathrm{r}=0.04$ \\
\hline & ns & ns & $p<0.05$ & ns & ns & ns & ns & ns \\
\hline \multirow[t]{2}{*}{$M T 1 B$} & & $\mathrm{r}=0.70$ & $\mathrm{r}=0.49$ & $\mathrm{r}=0.62$ & $r=0.65$ & $\mathrm{r}=0.65$ & $\mathrm{r}=0.49$ & $\mathrm{r}=0.07$ \\
\hline & & $p<0.005$ & $p<0.05$ & $p<0.005$ & $p<0.005$ & $p<0.005$ & $p<0.05$ & ns \\
\hline \multirow[t]{2}{*}{$M T 1 E$} & & & $\mathrm{r}=0.65$ & $\mathrm{r}=0.40$ & $\mathrm{r}=0.34$ & $\mathrm{r}=0.81$ & $\mathrm{r}=0.73$ & $\mathrm{r}=-0.24$ \\
\hline & & & $p<0.005$ & ns & ns & $p<0.0001$ & $p<0.005$ & ns \\
\hline \multirow[t]{2}{*}{$M T 1 F$} & & & & $\mathrm{r}=0.73$ & $\mathrm{r}=0.70$ & $\mathrm{r}=0.62$ & $\mathrm{r}=0.72$ & $\mathrm{r}=0.22$ \\
\hline & & & & $p<0.005$ & $p<0.005$ & $p<0.05$ & $p<0.005$ & ns \\
\hline \multirow[t]{2}{*}{$M T 1 G$} & & & & & $\mathrm{r}=0.82$ & $\mathrm{r}=0.59$ & $r=0.65$ & $\mathrm{r}=0.59$ \\
\hline & & & & & $p<0.0001$ & $p<0.05$ & $p<0.005$ & $p<0.05$ \\
\hline \multirow[t]{2}{*}{$M T 1 H$} & & & & & & $\mathrm{r}=0.40$ & $\mathrm{r}=0.43$ & $\mathrm{r}=0.46$ \\
\hline & & & & & & $\mathrm{ns}$ & $p<0.05$ & ns \\
\hline \multirow[t]{2}{*}{$M T 1 X$} & & & & & & & $\mathrm{r}=0.78$ & $\mathrm{r}=0.13$ \\
\hline & & & & & & & $p<0.0001$ & ns \\
\hline \multirow[t]{2}{*}{$M T 2 A$} & & & & & & & & $\mathrm{r}=0.03$ \\
\hline & & & & & & & & $\mathrm{ns}$ \\
\hline
\end{tabular}

ns: Not significant.

Expression Master Mix (Applied Biosystems, Carlsbad, CA, USA). The results of mRNA expression were normalized to the mRNA expression of $\beta$-actin. For the PCR reactions, the following TaqMan ${ }^{\circledR}$ primers and probes utilized in our previous studies were used: MT1A Hs00831826_s1, MT1B Hs01875377_s1, MT1E Hs01938284_g1, MT1F Hs00744661_sH, MT1G Hs02578922_gH, MT1H Hs00823168_g1, MT1X Hs04194245_g1, MT2A Hs01591333_g1, MT3 Hs00359394_g1, MT4 Hs00262914_m1, ACTB Hs99999903_m1 (Applied Biosystem) $(29,30)$. All of the reactions were performed in triplicates. Polymerase was activated at $50^{\circ} \mathrm{C}$ for $2 \mathrm{~min}$. Initial denaturation was performed at $94^{\circ} \mathrm{C}$ for $10 \mathrm{~min}$ followed by 40 cycles of denaturation at $94^{\circ} \mathrm{C}$ for $15 \mathrm{~s}$, an annealing step and synthesis at $60^{\circ} \mathrm{C}$ for $1 \mathrm{~min}$. Relative expression (RQ) of the studied MT isoforms was calculated using the $\Delta \Delta \mathrm{Ct}$ method. The mean expression of MT isoforms of the $17 \mathrm{NG}$ cases was used as calibrator for MT isoform expression in all the analyzed samples.

Statistical analysis. Prism 5.0 (GraphPad, La Jolla, CA, USA) statistical software was used for statistical analysis. One-way analysis of variance (ANOVA) was utilized to determine significant differences in mRNA RQs for MT isoforms in all the analyzed groups. The Bonferroni multiple comparison test was subsequently used to adjust the obtained results for multiple testing corrections and determine the differences of MT mRNA expression levels between two particular groups. Correlations between the relative expression (RQ) of MT mRNAs were analyzed using Spearman correlation test, whereas correlation of expression with patient age was performed utilizing the Pearson correlation test. In all the analyses, results were considered statistically significant when $p<0.05$. 

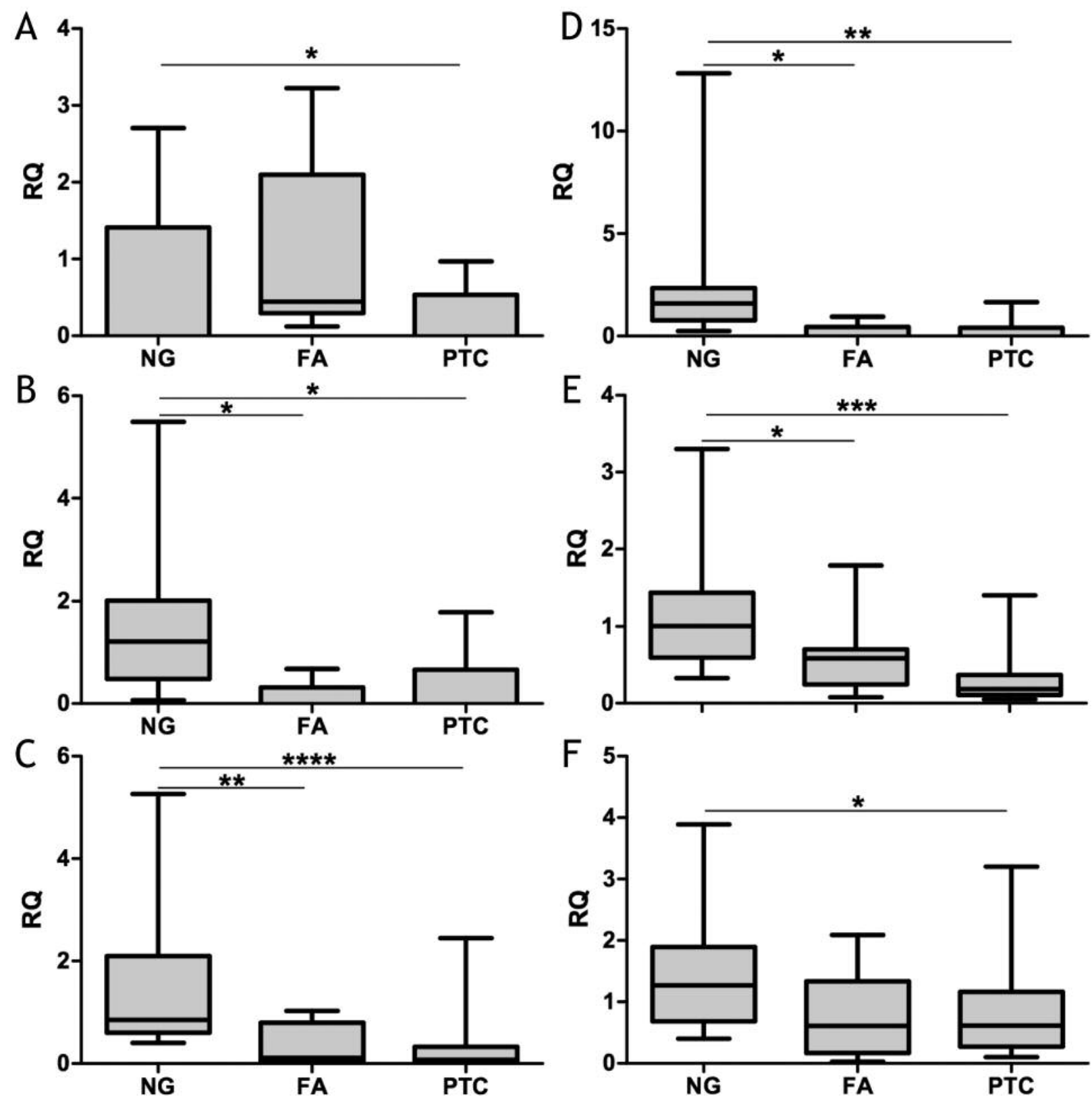

Figure 1. Relative expression (RQ) of metallothionein (MTs) MT1A (A), MT1E (B), MT1F (C), MT1G (D), MT1X (E) and MT2A (F) in nodular goiter (NG), follicular adenoma (FA), and papillary thyroid cancer (PTC). Data are presented as box-plots. Significantly different at $* p<0.05$, $* * p<0.005, * * * p<0.0005, * * * * p<0.0001 ;$ Bonferroni multiple comparison test.

\section{Results}

Relative expression of analyzed MT isoforms is summarized in Table II, however, no MT4 mRNA expression was detected in any of the analyzed samples. One-way ANOVA analysis revealed significant differences in mRNA RQs of MTlA $(p<0.05)$, MTlE $(p<0.005)$, MTlF $(p<0.0001), M T 1 G$ $(p<0.005)$, MT1X $(p<0.0005)$ and MT2A $(p<0.005)$ within analyzed samples. No significant differences were noted in mRNA RQs of $M T 1 B, M T 1 H$ and $M T 3$.

Post hoc analysis using Bonferroni multiple comparison test revealed significant differences in the particular MT isoforms RQs in the study group. A significantly lower expression of MTIA mRNA was observed in PTC compared 
Table IV. Correlation between mRNA expression of analyzed functional metallothionein (MT) isoforms in follicular adenoma cases.

\begin{tabular}{|c|c|c|c|c|c|c|c|c|}
\hline Isoform & $M T 1 B$ & MT1E & $M T 1 F$ & $M T 1 G$ & $M T 1 H$ & $M T 1 X$ & $M T 2 A$ & MT3 \\
\hline \multirow[t]{2}{*}{ MT1A } & $\mathrm{r}=0.50$ & $\mathrm{r}=0.56$ & $\mathrm{r}=0.32$ & $\mathrm{r}=0.28$ & $\mathrm{r}=0.53$ & $\mathrm{r}=0.18$ & $\mathrm{r}=0.20$ & $\mathrm{r}=0.02$ \\
\hline & $\mathrm{ns}$ & ns & ns & ns & ns & ns & ns & ns \\
\hline \multirow[t]{2}{*}{$M T 1 B$} & & $\mathrm{r}=0.35$ & $\mathrm{r}=-0.10$ & $\mathrm{r}=-0.23$ & $\mathrm{r}=0.28$ & $\mathrm{r}=0.23$ & $\mathrm{r}=-0.08$ & $\mathrm{r}=0.24$ \\
\hline & & ns & ns & ns & ns & ns & ns & ns \\
\hline \multirow[t]{2}{*}{$M T 1 E$} & & & $\mathrm{r}=0.60$ & $\mathrm{r}=0.37$ & $\mathrm{r}=0.36$ & $\mathrm{r}=0.54$ & $\mathrm{r}=0.59$ & $\mathrm{r}=-0.36$ \\
\hline & & & $p<0.05$ & ns & ns & ns & $p<0.05$ & ns \\
\hline \multirow[t]{2}{*}{$M T 1 F$} & & & & $\mathrm{r}=0.92$ & $\mathrm{r}=0.64$ & $\mathrm{r}=0.85$ & $\mathrm{r}=0.85$ & $\mathrm{r}=-0.27$ \\
\hline & & & & $p<0.0001$ & $p<0.05$ & $p<0.05$ & $p<0.0001$ & ns \\
\hline \multirow[t]{2}{*}{$M T 1 G$} & & & & & $\mathrm{r}=0.66$ & $\mathrm{r}=0.69$ & $\mathrm{r}=0.85$ & $\mathrm{r}=-0.19$ \\
\hline & & & & & $p<0.05$ & $p<0.05$ & $p<0.005$ & ns \\
\hline \multirow[t]{2}{*}{$M T 1 H$} & & & & & & $\mathrm{r}=0.58$ & $\mathrm{r}=0.40$ & $\mathrm{r}=0.32$ \\
\hline & & & & & & $p<0.05$ & ns & ns \\
\hline \multirow[t]{2}{*}{$M T 1 X$} & & & & & & & $\mathrm{r}=0.69$ & $\mathrm{r}=-0.14$ \\
\hline & & & & & & & $p<0.05$ & $\mathrm{~ns}$ \\
\hline \multirow[t]{2}{*}{$M T 2 A$} & & & & & & & & $\mathrm{r}=-0.34$ \\
\hline & & & & & & & & ns \\
\hline
\end{tabular}

ns: Not significant.

Table V. Correlation between mRNA expression level of analyzed functional metallothionein (MT) isoforms in papillary thyroid carcinoma cases.

\begin{tabular}{|c|c|c|c|c|c|c|c|c|c|}
\hline Isoform & MT1A & $M T 1 B$ & MT1E & $M T 1 F$ & $M T 1 G$ & MT1H & MT1X & $M T 2 A$ & MT3 \\
\hline \multirow[t]{2}{*}{$M T 1 A$} & & $\mathrm{r}=0.36$ & $\mathrm{r}=0.63$ & $\mathrm{r}=0.57$ & $\mathrm{r}=0.50$ & $\mathrm{r}=0.29$ & $\mathrm{r}=0.48$ & $\mathrm{r}=0.46$ & $\mathrm{r}=0.26$ \\
\hline & & ns & $p<0.0001$ & $p<0.0005$ & $p<0.05$ & ns & $p<0.05$ & $p<0.05$ & ns \\
\hline \multirow[t]{2}{*}{$M T 1 B$} & & & $\mathrm{r}=0.15$ & $\mathrm{r}=0.31$ & $\mathrm{r}=0.26$ & $\mathrm{r}=0.49$ & $\mathrm{r}=0.07$ & $\mathrm{r}=0.29$ & $\mathrm{r}=-0.29$ \\
\hline & & & $\mathrm{ns}$ & $\mathrm{ns}$ & $\mathrm{ns}$ & $p<0.05$ & $\mathrm{~ns}$ & $\mathrm{~ns}$ & $\mathrm{~ns}$ \\
\hline \multirow[t]{2}{*}{ MT1E } & & & & $r=0.65$ & $\mathrm{r}=0.64$ & $\mathrm{r}=0.41$ & $r=0.69$ & $\mathrm{r}=0.59$ & $\mathrm{r}=0.23$ \\
\hline & & & & $p<0.0001$ & $p<0.0001$ & $p<0.05$ & $p<0.0001$ & $p<0.005$ & ns \\
\hline \multirow[t]{2}{*}{$M T 1 F$} & & & & & $r=0.93$ & $\mathrm{r}=0.75$ & $\mathrm{r}=0.75$ & $\mathrm{r}=0.54$ & $\mathrm{r}=0.17$ \\
\hline & & & & & $p<0.0001$ & $p<0.0001$ & $p<0.0001$ & $p<0.05$ & $\mathrm{~ns}$ \\
\hline \multirow[t]{2}{*}{$M T 1 G$} & & & & & & $\mathrm{r}=0.80$ & $\mathrm{r}=0.76$ & $\mathrm{r}=0.52$ & $\mathrm{r}=0.34$ \\
\hline & & & & & & $p<0.0001$ & $p<0.0001$ & $p<0.05$ & $\mathrm{~ns}$ \\
\hline \multirow[t]{2}{*}{ MTIH } & & & & & & & $\mathrm{r}=0.60$ & $\mathrm{r}=0.34$ & $\mathrm{r}=0.18$ \\
\hline & & & & & & & $p<0.005$ & $\mathrm{~ns}$ & ns \\
\hline \multirow[t]{2}{*}{ MT1X } & & & & & & & & $\mathrm{r}=0.75$ & $\mathrm{r}=0.23$ \\
\hline & & & & & & & & $p<0.0001$ & $\mathrm{~ns}$ \\
\hline \multirow[t]{2}{*}{$M T 2 A$} & & & & & & & & & $\mathrm{r}=-0.05$ \\
\hline & & & & & & & & & ns \\
\hline
\end{tabular}

ns: Not significant.

to NG $(p<0.05)$. Significant down-regulation was also noted for other MT isoforms in PTC in comparison to NG: MTIE $(p<0.05)$, MT1F $(p<0.0001), M T 1 G(p<0.005)$, MT1X $(p<0.0005)$ and $M T 2 A(p<0.05)$. In addition, significant down-regulation of $M T 1 F$ and $M T 1 G$ in FA as compared to NG was observed $(p<0.005$ and $p<0.05$, respectively) (Figure 1).

Statistical analysis using the Mann-Whitney test revealed no significant associations between mRNA expression levels and primary tumor size or presence of lymph node metastases (data not shown). Moreover, no significant correlations were found with patient age at diagnosis and mRNA RQs of particular MT isoforms (Pearson correlation test) in benign lesions (NG, FA) and PTC (data not shown). Spearman correlation test revealed significant correlations of mRNA expressions of analyzed in MT isoforms in benign and malignant thyroid lesions (Tables III-V). 


\section{Discussion}

It is very difficult to effectively control all nodular lesions in multinodular goiter, as PTCs are very often diagnosed upon histopathological examination and detected in up to $35.6 \%$ of potentially benign thyroid glands upon post-mortem autopsy (10). Therefore, it is important to identify new markers based on ancillary techniques e.g. mRNA expression, which could improve the differentiation of benign from malignant thyroid lesions during FNA examination. It was already shown that expression of MT isoforms among thyroid tumor types differs significantly. Down-regulation of MTIE, MTIG, MTIX and $M T 2 A$ in PTC in comparison to benign thyroid lesions was shown by Ferrario et al. (26) and Huang et al. (28). The results of this study confirm the observations of other authors, however, we additionally demonstrated significantly lower expression of the MTIA and MTIF in PTC. No significant differences between expression of the MTIB, MTIH and MT3 in the analyzed cases were shown. Although the immunohistochemical study of Nartey et al. demonstrated higher MT expression in PTC (24), the recently published study by Królicka et al. showed lower MT1/2 protein expression in PTC as compared to NG (25). Our results support the latter finding.

The potential mechanism underlying the differences in mRNA expression of MT isoforms between the analyzed lesions have not yet been determined, however, the redox potential of thyroid cells during malignant transformation may impact the level of MT expression due to the redox sensitive nature of regulatory mechanism $(14,20)$. The observed strong positive correlations between mRNA expression of particular MT isoforms seem to support this hypothesis.

Nevertheless based on the obtained results, determination of MT mRNA expression could be useful in identification of cancerous nodules within NG, as MTIA, MTIE, MTIF, $M T 1 G, M T 1 X$ and $M T 2 A$ were significantly down-regulated in PTCs. It seems that determination of single MT isoforms would not be sufficient to discriminate benign and malignant lesions as significant down-regulation of MTIE, MTIF and $M T I X$ was also be noted in FA samples compared to NG and did not significantly differ from the levels determined in PTCs. Therefore, it seems that combined determination of MTIA, MTIE, MTIF, MTIG, MTIX and MT2A would be able to distinguish the underlying malignancy within the NG structure and also combined with cytological assessment of FNA could increase the detection of malignant changes.

However, it should be underscored that the results of this study are preliminary and of limited potential as determination of MT mRNA levels was performed in tissues biopsied following surgical removal of thyroid lesions. In order to fully validate the potential utility of our preliminary findings, further studies undertaken on FNA of thyroid lesions are necessary to determine the clinical significance of presented results. In summary, expressions of functional MT gene isoforms may be potential markers of malignant transformation of thyroid tissues and therefore should be of clinical relevance in the diagnostic procedures of this endocrine gland.

\section{References}

1 Sherman SI: Thyroid carcinoma. Lancet 361(9356): 501-511, 2003.

2 Ogilvie JB, Piatigorsky EJ and Clark OH: Current status of fineneedle aspiration for thyroid nodules. Adv Surg 40: 223-238, 2006.

3 Krajowy Rejestr Nowotworów, www.onkologia.org.pl/now otwory-tarczycy-c73/, accesed online: 23.07.2017

4 Cibas ES, Ali SZ: The Bethesda System for reporting thyroid cytopathology. Thyroid 19(11): 1159-1165, 2009.

5 Cooper DS, Doherty GM, Haugen BR, Kloos RT, Lee SL, Mandel SJ, Mazzaferri EL, McIver B, Pacini F, Schlumberger M, Sherman SI, Steward DL and Tuttle RM: Revised American Thyroid Association management guidelines for patients with thyroid nodules and differentiated thyroid cancer. Thyroid 19(11): 1167-1214, 2009.

6 Wojtczak B, Sutkowski K, Bolanowski M, Łukieńczuk T, Lipiński A, Kaliszewski K, Głód M and Domosławski P: The prognostic value of fine-needle aspiration biopsy of the thyroid gland - analysis of results of 1078 patients. Neuro Endocrinol Lett 33(5): 511-516, 2012.

7 Sobrinho-Simoes M, Eloy C, Magalhães J, Lobo C and Amaro T: Follicular thyroid carcinoma. Mod Pathol 24: S10-18, 2011.

8 Haugen BR, Alexander EK, Bible KC, Doherty GM, Mandel SJ, Nikiforov YE, Pacini F, Randolph GW, Sawka AM, Schlumberger M, Schuff KG, Sherman SI, Sosa JA, Steward DL, Tuttle RM and Wartofsky L: 2015 American Thyroid Association Management guidelines for adult patients with thyroid nodules and differentiated thyroid cancer: The American Thyroid Association guidelines task force on thyroid nodules and differentiated thyroid cancer. Thyroid 26(1): 1-133, 2016.

9 Slijepcevic N, Zivaljevic V, Marinkovic J, Sipetic S, Diklic A and Paunovic I: Retrospective evaluation of the incidental finding of 403 papillary thyroid microcarcinomas in 2466 patients undergoing thyroid surgery for presumed benign thyroid disease. BMC Cancer 15: 330, 2015.

10 Harach HR, Franssila KO and Wasenius VM: Occult papillary carcinoma of the thyroid. A 'normal' finding in Finland. A systematic autopsy study. Cancer 56(3): 531-538, 1985.

11 Margoshes M, Vallee B: A cadmium protein from equine kidney cortex. J Am Chem Soc 79: 1813-1814, 1957.

12 Coyle P, Philcox JC, Carey LC and Rofe AM: Metallothionein: the multipurpose protein. Cell Mol Life Sci 59(4): 627-647, 2002.

13 Pedersen MO, Larsen A, Stoltenberg M and Penkowa M: The role of metallothionein in oncogenesis and cancer prognosis. Prog Histochem Cytochem 44(1): 29-64, 2009.

14 Dziegiel P, Pula B, Kobierzycki C, Stasiolek M and PodhorskaOkolow M: Metallothioneins: structure and functions. Adv Anat Embryol Cell Biol 218: 3-20, 2016.

15 Pula B, Domoslawski P, Podhorska-Okolow M and Dziegiel P: Role of metallothioneins in benign and malignant thyroid lesions. Thyroid Res 5(1): 26, 2012. 
16 Mididoddi S, McGuirt JP, Sens MA, Todd JH and Sens DA: Isoform-specific expression of metallothionein mRNA in the developing and adult human kidney. Toxicol Lett 85(1): 17-27, 1996.

17 Werynska B, Pula B, Muszczynska-Bernhard B, Gomulkiewicz A, Piotrowska A, Prus R, Podhorska-Okolow M, Jankowska R and Dziegiel P: Metallothionein $1 \mathrm{~F}$ and $2 \mathrm{~A}$ overexpression predicts poor outcome of non-small cell lung cancer patients. Exp Mol Pathol 94(1): 301-308, 2012.

18 Mao J, Yu H, Wang C, Sun L, Jiang W, Zhang P, Xiao Q, Han $\mathrm{D}$, Saiyin $\mathrm{H}$, Zhu J, Chen T, Roberts LR, Huang $\mathrm{H}$ and $\mathrm{Yu} \mathrm{L}$ : Metallothionein MT1M is a tumor suppressor of human hepatocellular carcinomas. Carcinogenesis 33(12): 2568-2577, 2012

19 Stennard FA, Holloway AF, Hamilton $\mathrm{J}$ and West AK: Characterisation of six additional human metallothionein genes. Biochim Biophys Acta 1218(3): 357-365, 1994.

20 Dziegiel P, Pula B, Kobierzycki C, Stasiolek M and PodhorskaOkolow M: The role of metallothioneins in carcinogenesis. Adv Anat Embryol Cell Biol 218: 29-63, 2016.

21 Dziegiel P, Pula B, Kobierzycki C, Stasiolek M and PodhorskaOkolow M: Metallothionein-3. Adv Anat Embryol Cell Biol 218: 21-27, 2016.

22 Surowiak P, Materna V, Maciejczyk A, Pudełko M, Markwitz E, Spaczyński M, Dietel M, Zabel M and Lage H: Nuclear metallothionein expression correlates with cisplatin resistance of ovarian cancer cells and poor clinical outcome. Virchows Arch 450(3): 279-285, 2007

23 Cai L, Cherian MG: Zinc-metallothionein protects from DNA damage induced by radiation better than glutathione and copperor cadmium-metallothioneins. Toxicol Lett 136(3): 193-198, 2003.

24 Nartey N, Cherian MG and Banerjee D: Immunohistochemical localization of metallothionein in human thyroid tumors. Am J Pathol 129(1): 177-182, 1987.
25 Krolicka A, Kobierzycki C, Puła B, Podhorska-Okołów M, Piotrowska A, Rzeszutko M, Rzeszutko W, Rabczyński J, Domosławski P, Wojtczak B, Dawiskiba J and Dzięgiel P: Comparison of metallothionein (MT) and Ki-67 antigen expression in benign and malignant thyroid tumours. Anticancer Res 30(12): 4945-4949, 2010.

26 Ferrario C, Lavagni P, Gariboldi M, Miranda C, Losa M, Cleris L, Formelli F, Pilotti S, Pierotti MA and Greco A: Metallothionein $1 \mathrm{G}$ acts as an oncosupressor in papillary thyroid carcinoma. Lab Invest 88(5): 474-481, 2008.

27 Finn SP, Smyth P, Cahill S, Streck C, O’Regan EM, Flavin R, Sherlock J, Howells D, Henfrey R, Cullen M, Toner M, Timon $\mathrm{C}$, O'Leary JJ and Sheils OM: Expression microarray analysis of papillary thyroid carcinoma and benign thyroid tissue: emphasis on the follicular variant and potential markers of malignancy. Virchows Arch 450(3): 249-260, 2007.

28 Huang Y, Prasad M, Lemon WJ, Hampel H, Wright FA, Kornacker K, LiVolsi V, Frankel W, Kloos RT, Eng C, Pellegata NS and de la Chapelle A: Gene expression in papillary thyroid carcinoma reveals highly consistent profiles. Proc Natl Acad Sci USA 98(26): 15044-15049, 2001.

29 Werynska B, Pula B, Muszczynska-Bernhard B, Gomulkiewicz A, Jethon A, Podhorska-Okołow M, Jankowska R and Dziegiel P: Expression of metallothionein-III in patients with non-small cell lung cancer. Anticancer Res 33(3): 965-974, 2013.

30 Werynska B, Pula B, Muszczynska-Bernhard B, Gomulkiewicz A, Piotrowska A, Prus R, Podhorska-Okolow M, Jankowska R and Dziegiel P: Metallothionein $1 \mathrm{~F}$ and 2A overexpression predicts poor outcome of non-small cell lung cancer patients. Exp Mol Pathol 94(1): 301-308, 2013.

Received June 5, 2017

Revised June 27, 2017

Accepted July 24, 2017 